\title{
Use of Artificial Intelligence in the Field of Sustainable Architecture: Current Knowledge
}

AUTHORS:

Veronika Krausková ${ }^{\star}$

Henrich Pifko²

1, 2 Slovak University of Technology in Bratislava, Faculty of Architecture and Design, Institute of Ecological and Experimental Architecture, Slovakia

\section{${ }^{*}$ CORRESPONDING AUTHOR}

E-mail: veronika.krauskova@stuba.sk

ARTICLE INFO

Sent: Nov 15, 2020

Accepted: Feb 11, 2021

\begin{abstract}
:
Innovative technologies help automate the work of the designer. A 3D model of the building can be used to calculate the required values. This will also allow you to create associative sections that, when changing the geometry of the 3D model, automatically adjust the drawn elements on the resulting 2D drawing. Information technologies enable participants from all over the world to work on one project and, thanks to the BIM (building information modelling) method, to design buildings during their life cycle more efficiently. At present, critical studies are published on interoperability in BIM and its lack of coordination or amount of information that is misinterpreted, etc. However, working in BIM is the most effective way to use computer technology to design buildings. There is a lot of information about the building in the 3D model itself, which can also be used for purposes other than construction (building management, reconstruction). But how to process a large amount of information in a 3D model? Many buildings already have their 3D models shared on cloud platforms, these contain information that could help, for example, find solutions for green construction using artificial intelligence (AI). We meet with Al every day. It supports internet search engines, predicts auto-completion words as you type. Al can also be found in architecture - not only as visions at exhibitions, but also in research on process optimization in BIM.
\end{abstract}

\section{KEYWORDS:}

artificial intelligence, Al, building information model, BIM, generative adversarial network, GAN, architecture, sustainability

\section{INTRODUCTION}

Artificial intelligence $(\mathrm{Al})$ is used in many industries, typical examples being "smart assistants" (Siri, Alexa), chatbots for marketing and customer service, stock market robo advisors, disease mapping and tools to predict their spread. Al is often encountered in everyday life without our knowledge, used for example in spam filters, Internet search engines, advertisement engines and recommendations for movies or songs on streaming services [1]

Simply put, Al works on the principle of statistics from the provided data, where a computer program can find relationships based on many iterations of a certain scheme without programming these connections in advance, and then it can predict the most probable result or offer and possibly implement measures that will lead to the promotion of the desired or elimination of the undesired result.

\section{Research objective}

One of the current topics of application of information technology (IT) to support architectural design and optimization of building operation is the use of artificial intelligence ( $\mathrm{AI})$. BIM is a powerful tool not just in the phase of early design, when we think about the architecture of the building, but for optimizing the whole building process itself during the lifecycle and there is still a lot of space for improvement as a critical study declares [2]. And the design of sustainable architecture is also the topic of the day. In our study, we consider the potential of combining and complementing these approaches. After gaining knowledge of the applicability of $\mathrm{Al}$ in the optimization of architecture and its operation, we will use it to prepare bases for creation of the BIM model of the building of the Faculty of Architecture and Design of the STU. The model database will be used as input for $\mathrm{Al}$ algorithms in the process of optimizing the life cycle of the building - the goal is to significantly reduce the carbon footprint (a characteristic indicator of the degree of sustainability) of the 
faculty building. The first step to achieve this goal (and the content of this study) is to analyse the Al practice used so far in architecture and assess their potential to fulfil the vision of a more sustainable building. Only based on this assessment will we specify the working hypotheses and applicable research methods.

\section{Hypothesis}

Artificial intelligence is used only rarely in architecture and there is little experience on which we can rely. Only the results of the first stages of research and the experience from their practical application will allow the precise formulation of hypotheses. However, we can assume that $\mathrm{Al}$ will be applicable in some areas. This mainly entails the prediction of user behaviour during building operation, which is not fully algorithmic, but its patterns can be detected and used by AI to ensure the quality of the indoor environment and to adapt it to user needs and requirements. Some of the parameters determined in this way can be applied in the process of designing or modifying the building. One of the hypotheses we are considering is the assumption that $\mathrm{Al}$ will make it possible to express critical numbers of users and patterns of use for which natural ventilation is no longer sufficient to ensure satisfaction with the indoor environment. To confirm or refute this hypothesis (and other similar ones), it is necessary to create a building model to which it will be possible to apply Al. This is beyond the scope of this study, but it will be a key point in our research.

\section{SOURCES}

An important study material for us is the exhibition on $\mathrm{Al}$ in architecture in Paris [3]. There we find the work of Stanislas Chaillou [4], who is a data scientist and architect. For example, he addresses the use of $\mathrm{Al}$ in the design of building layout [5], but he also perceives architecture as a form of visual art, and he uses $\mathrm{Al}$ to interpret the Baroque style [6].

The technical problems of connecting architecture and $\mathrm{Al}$ are addressed by the BIMBOT project [7]. When creating a building design, it is necessary to process a lot of construction information, and it is reasonable to have it stored in BIM (Building information model). The BIMBOT study deals with the optimization of building design process and the data structure in BIM database.

The design of energy-efficient interior space and the thermal comfort in BIM is the subject of the study of Ma, Liu, Shang [8]. It is an example of the synthesis of BIM, Al, topics of sustainable architecture, and indoor environment quality.

Ekaterina Petrova [9] is exploring the possibility of gaining knowledge from the real operation of buildings for sustainable design in BIM. She addresses ways to integrate acquired knowledge and semantic data modelling (i.e., data structuring methods that add meanings and relationships in the model [10]) to support evidence-based building design decisions. With this approach, BIM brings progress and new solutions to architecture. The next step here can be the use of Al.

\section{Historical development}

At the exhibition on $\mathrm{Al}$ in architecture [11], Stanislas Chaillou states that "technological progress towards $\mathrm{Al}$ is the result of gradual technical development rather than a revolutionary discovery". He considers four events (modularity, CAD, parametric design, $\mathrm{Al}$ ) to be the milestones of this technical development, which have contributed to the systematization in architecture over the last hundred years. The individual milestones are then described by Chaillou [11] as follows:

Modularity. Its purpose was to simplify construction in terms of technical solutions for a more affordable architecture. Walter Gropius had already dealt with it in Bauhaus. Subsequently, Richard Buckminster Fuller brought a more systematic view of the module, and his Dymaxion House takes modular housing to the extreme, demonstrating a concept for industrial production. Le Corbusier refined the "modulor" by the human scale in the "Unité d'habitation". The idea of modularity also influenced urbanism; in the early sixties, projects such as Achigram's "Plugin City" encouraged the creation of an entire modular city. However, the initial elegant idea soon reached its limits, because architecture reflects different needs and cannot be simplified into a structure of simple "boxes". The undoubted benefit of modularity is more efficient construction where such a structured system is suitable.

Computer-aided design - CAD. The question of the possibility of using computer technology to support design was raised in the early fifties. One of the first attempts was PRONTO. This software -released as a prototype in 1959 for the design of engineering components- opened a discussion about the use of such software in architecture. At MIT, the AMG (Architecture Machine Group) was formed in 1967 to "explore how machines can improve the creative process and focus on the production of architecture as a whole." In 1976, Cedric Price in Cambridge followed up on the work of AMG and created the "Generator" the idea of $\mathrm{Al}$ as a constantly evolving autonomous building that "intelligently" responds to the needs of its users. A very famous name in the use of software in architecture is Gehry Technologies - a software company founded by Frank Gehry and Jim Glymph in 1980. Over the years, the work of architects has changed dramatically, and the development of computer technologies enabled their more sophisticated use, such as $3 D$ modelling.

Parametric design. The original idea dates back to the beginnings of the use of computer technology. Around 1960, Luigi Moretti suggested nineteen defining parameters for the "Stadium N" project and established strict procedures that were responsible for the building shape. A few years later, Ivan Sutherland applied similar principles creating SketchPad software. The parametric approach simplifies design and modelling, the architect does not have to deal with frequent and repetitive tasks. It helps to model complex shapes more easily according to the input in the form of parameters; if we change any parameter, the program can immediately provide a revised design reflecting the changed parameter. 
In architecture, the term "parameter" can be understood in different ways. For example, if we define the height of the walls of one floor as a parameter in simple 3D modelling and change this parameter later, the program recalculates all walls to the desired height, without the need to change the height of the walls individually. Zaha Hadid uses a much more complex way of architectural parameterization - combining mathematics with the parametric design in architecture. Her work is often the result of a set of rules in the program, creating unprecedented control over the geometry of a building. Each architectural decision is translated into a set of parameters and the result is a specific shape of the building. In 2000, David Rutten developed the Grasshopper program, which provides a user interface for visual parametric programming.

BIM (building information model/modelling) is also related to parametric design. Around the year 2000 the idea emerged (e.g., Philip Bernstein from Autodesk) that each element in a 3D building model is a function of parameters (properties) and these parameters control and document the shape of each object in the model.

Artificial intelligence. The use of Al today marks a new era of architectural design. Meaning "use the human brain as a model for machine logic", the concept of Al was created in 1956 by mathematician John McCarthy. Instead of designing a deterministic model, he created a series of variables and rules, wherein Al creates parameters from the information gathered. Once the learning phase is completed, the computer can generate solutions that are not only a response to predefined parameters and algorithms, but also the result of processing the information received during the learning phase. Al with its concept "breaks down" the idea of parametricism in architecture: even if not all rules are defined, the computer can find hidden phenomena and it can imitate them. This is a big step from heuristic to statistical modelling.

After 1980, computer performance increased significantly, and Al research took a second breath. Gradually, development progressed to machine learning (ML) using "layered" models of neural networks that resemble the structure of the human brain. As a result, the "machine" can now solve complex problems, including architecture design and management.

\section{METHODS AND MATERIALS}

We investigate the assumption that $\mathrm{Al}$ can be used effectively as a tool in architectural design, to obtain operational data, find context, and use Al knowledge and outputs to support the design of sustainable architecture in BIM. We have examined studies on BIMBOT, the work of Chaillou and the study of Petrov (which we consider to be substantial, as it examines the issue in detail). At this stage of the research, our goal is to:

- select the most up-to-date knowledge about $\mathrm{Al}$ in architecture by studying existing research and/or case studies;

- summarize terminology in the field of $\mathrm{Al}$;

- analyse and study selected scientific works;

- evaluate the findings.

\section{Al terminology}

Artificial intelligence $(A I)$ - the discipline of creating and using intelligent devices [12]

Machine learning (ML) - refers to the systems that learn through experience [12]

Deep learning $(D L)$ - refers to systems that learn through experience from large data sets [12]

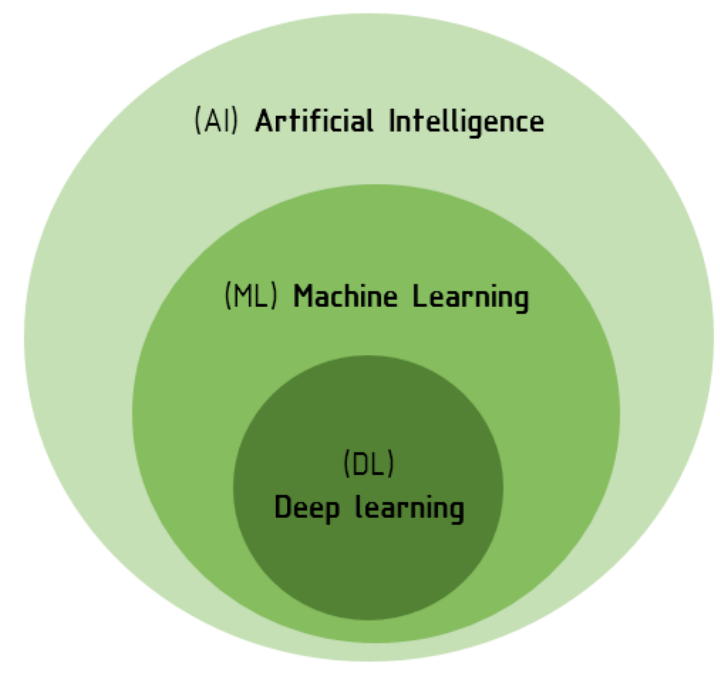

Figure 1: Relationship between Machine Learning and Deep Learning. According to Raghav Sharma [2]

Artificial neural network ( $A N N$ ) - is inspired by the functionality of electrochemical neural networks in human and animal brains. ANN can work with only a few neurons with one hidden layer to be an opponent in a board game. By adding more neurons and hidden layers, ANN can handle more complex problems. Deep learning uses ANN with at least two hidden layers, each of them containing many neurons. It is assumed that a neural network with three hidden layers can solve problems of any complexity. [12] [13]

Generative adversarial network (GAN) - ANN, which is mainly used to create realistic images. [14]

Natural language processing (NLP) - Al that can understand the language. [12]

Narrow / weak Al (ANI) - Al that is designed to solve simple or limited problems. [15]

Artificial general intelligence $(A G I)$ - Al, which is not limited to a specific area and can solve every problem that a person can handle (sometimes also called strong or full $\mathrm{Al}$ ). [14]

Artificial superintelligence (ASI) - intelligence that has better abilities than the average person. [14]

Singularity in $\mathrm{Al}$ - the moment when Al becomes so autonomous and intelligent that it can generate smarter and more autonomous Al. [14] 


\begin{tabular}{|c|c|c|c|}
\hline I. Wave & II. Wave & III. Wave & IV. Wave \\
\hline 1970-1990 & 2000-2020 & 2020-2030 & $2030 \longrightarrow$ \\
\hline $\begin{array}{l}\text { - "Good old- } \\
\text { fashioned“ Al } \\
\text { - Symbolic } \\
\text { - Heuristic } \\
\text { - Rule-based } \\
\text { - Handcrafted } \\
\text { knowledge } \\
\text { "experts } \\
\text { systems“ }\end{array}$ & $\begin{array}{l}\text { - Statistical } \\
\text { learning } \\
\text { - Advanced text } \\
\text { - Language } \\
\text { - Vision } \\
\text { processing }\end{array}$ & $\begin{array}{l}\text { - Contextual } \\
\text { adaptation } \\
\text { - Ability to explain } \\
\text { decisions } \\
\text { - Can converse in } \\
\text { natural language }\end{array}$ & $\begin{array}{l}\text { AGI (Artificial } \\
\text { General } \\
\text { Intelligence) } \\
\text { ASI (Artificial } \\
\text { Superintelligenc } \\
\text { e) } \\
\text { Technological } \\
\text { singularity } \\
\text { - Strong Al }\end{array}$ \\
\hline Learning & Learning & Learning & Learning \\
\hline Perceiving $\square$ & Perceiving $\square$ & Perceiving $\square$ & Perceiving \\
\hline Abstracting $\square$ & Abstracting $\square$ & Abstracting $\square$ & Abstracting \\
\hline Reasoning $\square$ & Reasoning $\square$ & Reasoning $\square$ & Reasoning \\
\hline
\end{tabular}

Figure 2: Four waves of Al.

According to Six Kin Development and DARPA (GAO-18-142SP) [40], [41]

Data-driven $M L$ - Al that can autonomously increase its ability to solve problems without the supervision of experts. Based on the analysis of the provided data, Al algorithms can find a characteristic formula for the investigated phenomenon. [13]

Data mining - a branch of computer science, which is focused on the automated identification of the occurrence of a certain phenomenon in data sets (datasets). [16]

Big data - a large set of several sets of data that can be so different that they cannot be processed or stored in the same way. [16]

Data in the wild - data that is searchable and usable without the control of the author or expert. Using such data may be dangerous, unethical, or even criminal. Some Al algorithms GAN or ANN can learn to generate images, videos, or sounds that change the identity of the people shown and create a very credible fraudulent impression, the so-called "Deepfake". [16]

\section{AI APPLICATIONS IN ARCHITECTURAL PRACTICE}

\section{Generative adversarial network (GAN)}

Architecture is presented and recorded in a wide variety of ways, from a mere $2 \mathrm{D}$ representation of technical drawings to visualizations of architectural expression, so it is appropriate to use GAN for Al work with architecture. Chaillou [16] interprets GAN by analogy with teacher and student as two Al tools: Generator-student and Discriminator-teacher. The generator produces data, and the discriminator rates it with a "mark". These two tools compete; the generator tries to generate images in which the discriminator does not notice that they are not real, and the discriminator tries to reveal the difference between the generated and actual images. In the beginning, the generator "knows nothing" and produces only an equivalent of random noise, so the task of the discriminator (to distinguish between the generated and the actual image) is simple. After several repetitions (training sets), the generator "learns" to generate more realistic images and the discriminator "learns" to evaluate the images as real (true)-satisfactory, or as fake (false)unsatisfactory. The discriminator also provides feedback to the generator, by which the generator evolves in creating further images. An architect enters this process, influencing what GAN will eventually learn, with a suitable database of "training sets".

For example, we can use GAN after training through datasets of site shapes with associated building plans, so that GAN will generate the most suitable building shape based on the site shape provided. [17]

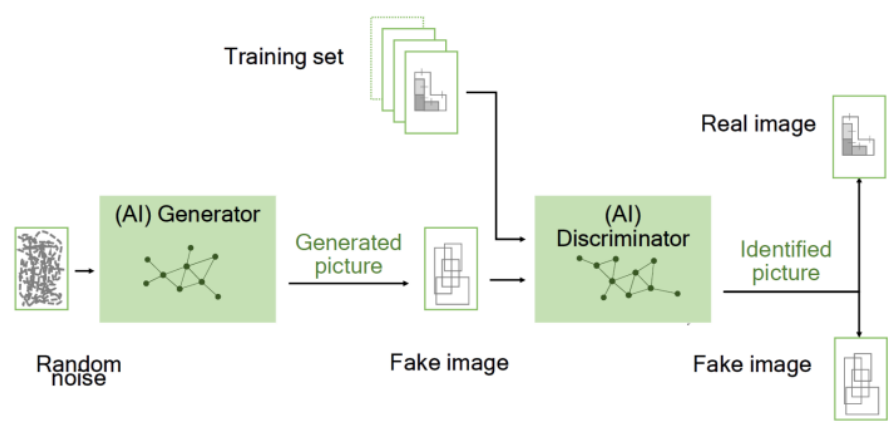

Figure 3: GAN, initial phase of training. According to S. Chaillou [5]

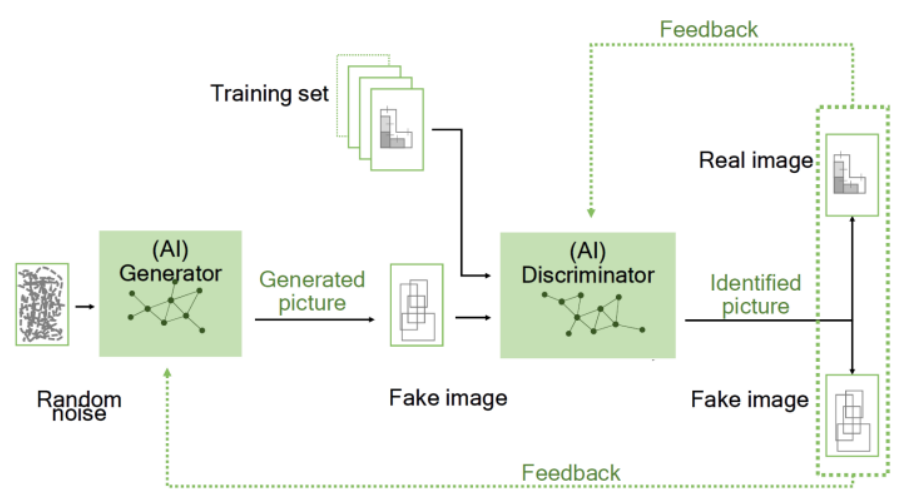

Figure 4: GAN process training.

According to S. Chaillou and Jirkovský (Humusoft) [5] 


\section{BIMBOT}

One of the possible answers to the question of how to optimize the complex issues of building design in BIM using $\mathrm{Al}$ is the BIMBOT software [18]. Designing a building with its support begins with defining priorities and then launching a generative iterative process enhanced by Al methods. It acts as an assistant during the design process and, through user interaction, optimizes various solutions for BIM models using intelligent objects. The technology in BIMBOT also uses the principles of PCG (procedural content generation - algorithms for computer game environments), as it is based on software that originally created $3 D$ sceneries for the creative industry.

BIMBOT technology operates with four main software components [19]: analysis of publicly available databases relating to the parameters of urban, technical and territorial regulations; integration of outputs from the analysed databases (defining possible mass of the building); application of evaluation criteria with the search for the most suitable overlap of solution requirements (orientation on the site, distances from neighbours); 2D/3D geometry limits for optimization technology based on metaheuristic software (e.g. relationships between rooms). At the same time, BIMBOT uses Al to evaluate the overlaps between these four components and looks for the overall optimization of the solution. It also has an interface with commercial CAD and BIM software.

Study of Ma, Liu, and Shang. Instead of calculating energy losses, this study [8] focuses on using knowledge of the conditions of individual thermal comfort of people in interiors and using ANN and BIM tools to create a plugin for commercial construction software to determine the ideal indoor location for a particular person - thus helping to optimize development of sustainable architecture.

\section{STUDY OF EKATERINA PETROVA}

Petrova's extensive work [20] is looking for a way to gain relevant knowledge from BIM projects and transform it into a "consultant" for designing sustainable buildings. Data would be obtained from existing buildings using $\mathrm{Al}$ analyses, creating an extensive database. It is important to know the processes in the databases to create more consistent and manageable BIM models. At the same time, it addresses the possibilities of designers' (architects, structural engineers) cooperation with Al. Designers' knowledge is a necessary and important part of the whole "digital" process, as are their skills and experience throughout the building's life cycle. If they are willing to share them, a database of very valuable information can be created.

Petrova formulated the main goals and outputs of her research in three points [21]:

1. Providing a framework to support efficient design in BIM, data mining, semantic data modelling, and subsequent provision of appropriate information that takes into account the defined design goal.
2. Demonstration of how a semantic cloud extended by characteristic patterns collects data about buildings - it can be used as a source of knowledge for the support of design.

3. Suggestion of how support can be provided to designers through a design software tool that can select knowledge for a specific user and project context, backed by an ecosystem of a rich project database.

BIM models are "filled" with information in the form of static data (materials, structures) and dynamic information (measurement of actual values during building operation $-\mathrm{CO}_{2}$ concentration, indoor and outdoor temperature, amount of water consumed). Thanks to that, BIM models become building databases. It often happens that BIM works only in the design phase or in the construction phase. The information contained in the models will thus remain unused during operation or renovation, it will become obsolete or will disappear with the entire unused BIM database model.

BIM database - the BIM model includes information about a specific project in specific conditions, with limits and priorities. Subsequently, additional information from the construction and operation of the building is added. Information about the building throughout its life cycle forms a robust database. Therefore, data processing involves the issue of volume, format, information structure, archiving method, and information type (for example, whether it concerns operation data tied to specific times).

Knowledge discovery in databases (KDD) - building life cycle data must be managed. Despite their software processing software in CDE (common data environment), the projects are very complex. [22] Building data may contain errors after the technological collection of building data during operation, or even in simulations and computational models during the design phase. A revision of BIM projects is therefore necessary.

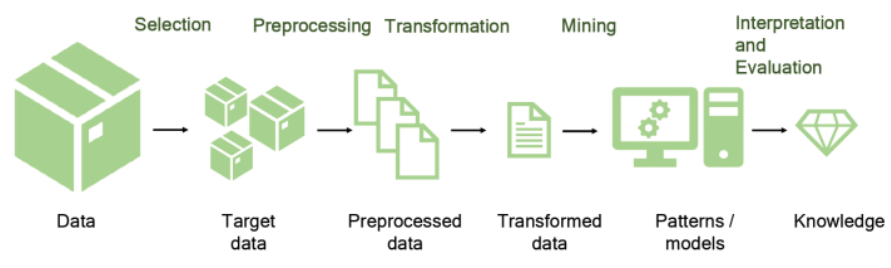

Figure 5: Process of "discovery of knowledge in a database" as defined by Fayyad et al. According to Petrova [9]

To search for useful knowledge in a database, statistical methods of $\mathrm{Al}$ (suitable for learning formulas or rules from data) and symbolic methods of $\mathrm{Al}$ (allowing various forms of deduction) would be used. [23] Therefore, integrating the ML concept to gain knowledge from semantic data modelling with a high-level support of decision-making in a coherent user-centred contextual ecosystem can be an important step towards a sustainable architecture.

The complexity of obtaining knowledge from the database can be divided into several areas [24]: 
1. Selection is understood as the search for relevant data in a large database for a specific problem. Finding connections in context requires understanding of database components.

2. Preparation includes data cleaning (removal of duplicates, solving of data conflicts, processing of incomplete or damaged data).

3. Data transformation means the transfer of the most important data with respect to our goal and the specified algorithm to a representative sample.

4. Data mining is the search for patterns in specific datasets, patterns that have not been known before.

5. Interpretation is the last step in evaluating the results of the data mining process, which includes their eventual visualization.

Potential challenges and limitations of using Al when working with a database are the responsibility for the validity of data and the processing of analytical algorithms to evaluate the information in the database. In this type of work, an industry expert is needed to evaluate the accuracy and processing of selected data. Important is the area of processing the so-called "unspoken" knowledge, which is knowledge gained through experience in specific situations. In this context, it is worthwhile to consider copyright laws and the impact of ethical issues of the use and sharing of the necessary information.

To assess data validity, it is important to know the data creation process and where Al can be used. [25] The database may contain data processed by predictive and descriptive methods. The predictive method is suitable, for example, for the energy needs of a building in terms of weather forecast, and the descriptive method is more about building management, where it describes the processes of operation. An important part of the data is the detection of anomalies and the diagnostics of buildings, for which it is necessary to know the behaviour of buildings to predict anomalies (e.g., errors in air conditioning, HVAC, building management systems) and improve building performance with respect to sustainability. Data-controlled measurements (as a characteristic pattern of energy consumption) are an important preventive method to detect anomalies that suddenly increase energy consumption. Another risky factor is the unpredictable user behaviour - for example, in control of lighting, opening of windows, heating and cooling, or water consumption).

Example of data mining in a database - 3D data is a building block when working on a BIM project. A common tool for data exchange is the export of the model to IFC (Industry Foundation Classes) format. Recent research [26] has shown that 3D data from an IFC file can be processed using Al to be transformed into spatial contexts and relationships. Subsequently, together with data-driven workflows of energy performance of buildings, they would seek to improve the energy balance of buildings by increasing the accuracy of the calculation [27].
However, the designer's knowledge (for the interpretation of the obtained data) remains the key, regardless of the method used.

Semantic data modelling - to be able to use the KDD results obtained by collecting data from the operation of buildings and by transferring information for the future decision-making process based on a holistic principle, a robust context infrastructure providing automation of interpretation and reuse of discovered knowledge in a dynamic cycle is necessary. Therefore, it is important to deal with the symbolic representation of knowledge and the formalization of meaning - semantics (the way data and commands are presented). [28] Significant efforts in this area have been made by the buildingSMART organization, which deals with the creation of IFC data. One of the forms of IFC is its transformation into the ifcOWL format (a standardized format for building data exchange via the web). [29] OWL in ifcOWL means Web Ontology Language (ontology represents knowledge and its mutual relations). [30]

Concepts of computer science may not sound important to architects. However, it is useful to know how to handle data processing in databases if we want to obtain a more meaningful BIM model, and how to handle information using $\mathrm{Al}$, where knowledge of databases is also welcome for the preparation of research data. When working on projects in BIM, an important document is the BIM execution plan (BEP), which determines the method of project processing and working with the data. When creating a BEP, it is beneficial to deal with the CDE environment in which the project is created and where communication takes place. Knowledge of working with data and databases can also be useful in data exchange and archiving BIM projects. It is essential to carefully consider and plan the specific use of technologies and software tools, as data volumes continue to grow over time. At the same time, it is necessary to minimize the risk of complications in interoperability, risk of information loss, and demanding conversions to various other formats due to the (in)compatibility of systems. For future research, the question is whether it would be appropriate to consider the requirement for data structuring and archiving of results as early as the BEP stage, or during the operation of the building.

LCA findings are most often associated with improvements to building energy balances in building simulations. This only partially fulfils the concept of cyclic feedback (design loop) between design and operation. A solution to acquiring knowledge and its categorization in the database is proposed by using $\mathrm{Al}$ in CDE. Architects and designers gain knowledge through work on individual projects, i.e., iteratively. Petrova [31] states in her work that knowledge from projects (iterations) could be captured in CDE thanks to working data from requirements, project limitations and the subsequent results. Al could accompany the architect from the beginning of his design thanks to CDE projects because the essential information can be analysed by Al right there. The data in CDE would be divided into semantic BIM data ( $\mathrm{Al}$ analysis would be performed), working solutions, 3D data (geometry), simulation data, and log data. CDE data is the basis of the database, connecting the building operation data (log data), requirements (descriptions), 
specifications (descriptions), consumption (descriptions) and user data (user log).

Case study - Petrova [32] used real building monitoring data for the demonstration. The Gigantum building $\left(34,000 \mathrm{~m}^{2}\right)$ in Aalborg, Denmark, opened in 1999 and has been renovated several times. It is a cultural and sports centre. It covers facilities such as ice rink, sports hall, concert hall, swimming pools, wellness, gym, conference rooms, cafe, and lobby. Operational data was collected using a network of 39 sensor nodes. Temperature $\left[{ }^{\circ} \mathrm{C}\right]$, relative humidity $[\%]$, air pressure $[\mathrm{hPa}]$, total volatile organic compounds (TVOC) [ppb], $\mathrm{CO}_{2}$ [ppm], lighting [lux], noise level $(\mathrm{dB})$ and movement were measured. All data is used to monitor indoor climate and thermal comfort of visitors, manage the building, and provide usage information. The measurement used covered the period from 16 February 2018 to 17 May 2018.

The Home2020 building $\left(132 \mathrm{~m}^{2}\right)$ is a detached family house completed in 2017. It consists of a living room and four other rooms - a kitchen, two bathrooms, a utility room, and a wardrobe. The house has underfloor heating, heat pump with heat recovery, controlled ventilation depending on $\mathrm{CO}_{2}$ levels and relative humidity. It also has a system of ventilation shafts and skylights. The ventilation system is automatically deactivated when windows or doors are opened. The external system of shading elements is controlled automatically. The building management system (BMS) monitors total energy consumption [MWh], consumption of the heat pump [kWh], ventilation system [kWh], control system [kWh] and kitchen appliances [kWh]. Temperature measurement is set to $\left[{ }^{\circ} \mathrm{C}\right]$ and the system measures outdoor temperature, supply and return air temperature, domestic hot water temperature, heat pump output temperature, return air relative humidity [\%], ventilation speed, and cold and hot water consumption $\left[\mathrm{m}^{3}\right]$. Indoor environment quality was evaluated by the sensors measuring temperature $\left[{ }^{\circ} \mathrm{C}\right]$, $\mathrm{CO}_{2}$ [ppm], relative humidity [\%], and flap opening [min / $\max$ ]. The measurement period was 1 December 2017 to 31 October 2018.

Data preparation - Gigantum data was processed and visualized using the Grafana platform. Observations from the sensors were captured in real time, but there was no direct access to the data at the time of the experiment, so it was necessary to prepare large amounts of CSV exports. Inconsistencies, missing measurements (probably sensor failure) and obvious errors (such as indoor temperature exceeding $400{ }^{\circ} \mathrm{C}$ ) were found in the data. [32]

In the case of Home2020, no platform was available, only directly obtained CSV data. Data for both cases was sorted for indoor environment only. No missing data or noise was found in the data.

Datasets with a representative (symbolic) value of specific data were created for data processing, so that the database could be handled more easily, because some measurements contained values too precise (e.g., 23,704365409749624). [33] This caused large demands on storage space and RAM.
After preparing the database, data mining can begin, where formulas or certain repeating sequences can be obtained. The search is performed by identifying the longest and most recurring representative string. After finding several strings, they will be evaluated again by a specialist, if interesting. Found data patterns of string repetitions - can be visualized by creating a graph, where the degree of their relations and the degree of "surprise" is visible more clearly. [34] This process can be repeated to evaluate other contexts. When we create a database of measurements from buildings and we want to add more values, it is good to categorize buildings by function. Subsequently, it remains to get the experience, knowledge, and facts about the buildings back to the architect in the design phase of other buildings. Therefore, there is a need for a single knowledge base. Specific information in this database would be searched using Al techniques.

If the information is to be valuable, it must remain in context. The evaluation itself and the assignment of meaning, value and importance is still up to the specialists. According to Petrova, the last element that is missing for the design of sustainable buildings in BIM is a "tailor-made" advice for a specific building type. Such advice should be guided by the evidence stored in the knowledge base. Using Al, we are then able to provide the architect with targeted advice for specific buildings and, if necessary, to find new insights in contexts that we may have missed. Petrova provides a design of the database structure and its conceptual architecture. [35]

Petrova does not offer exact guidance to architects but provides a suggestion on how and where to find relevant advice. It consists in creating a "two-way" database, the inputs of the collected data on buildings would be evaluated by experts in cooperation with Al. In the subsequent process of data processing, data would be subject to structuring and creating their meaningful representation for better management of data volume and context. Finally, in the last phase, which is the focus of all research and thus closing the imaginary circle between theory, practical knowledge and design, the knowledge gained would come from the database as advice or recommendation using a systematized principle of relevance assessment from the end "user" architect or other designer in collaboration with Al. Over time, the system of cooperation between construction industry experts and IT specialists with Al would be developed precisely thanks to the properties of Al to do exactly what they need to address a specific problem.

The proposal for cooperation between $\mathrm{Al}$ and experts is as follows: In large unexplored databases, $\mathrm{Al}$ is suitable for identifying repeating patterns. IT specialists know how to interpret formulas and find relationships between them. Construction professionals know how to contribute their knowledge and identify important patterns of "building behaviour". IT specialists then know how to integrate knowledge into context. This complex process is called crowdsourcing. [36] In her study, Petrova suggests a large database project, where knowledge would contribute to "collective truth." The system would allow you to enter knowledge and ratings using a user account and vote for the most appropriate solutions. The disadvantage of the system is that too many not quite relevant user ratings (or too few user 
ratings) will not help the large system. Petrova is suggesting a system with potential for the future. Cooperation between experts and technologies can be linked so that the design of sustainable buildings is based on evidence of already built projects.

\section{RESULTS}

We studied the most current approaches to the use of $\mathrm{Al}$ in the design of (sustainable) buildings. We focused on four authors representing four different approaches to this topic.

Chaillou, with the help of GAN, creates floor plans of buildings the arrangement of rooms in an apartment [5] or designs in a specific architectural style. [6] The usefulness of Al in the daily work of an architect is not yet clear. Chaillou's work is inspiring as a demonstration of the potential for a statistically best solution to a given problem. We see that:

1. The GAN method has its shortcomings in training sets. It requires a more extensive preparation of appropriate data to eliminate the noise of bad solutions which can lead to inappropriate patterns of Al-generated design solutions.

2. The limits are the knowledge and judgment of the architect in selecting datasets for GAN.

3. The Discriminator and the Generator must be properly "trained" to be stable enough because due their interdependence, the system may crash if there is an excessive imbalance.

4. Correct Object Identification - Al does not understand "intuitively" real-world concepts such as door handles and it is difficult and time-consuming to train Al so that it does not generate, for example, a door with ten handles instead of one.

$B I M B O T$ is a complex project and its disadvantage is the difficult identification of problems for the robustness of the apparatus and individual steps, their possible overlook and perhaps too much reliance on technologies that may not best evaluate all aspects and their importance in building design. There are certainly questions as to whether a system connected to a generative engine of computer games is able to respond to real building problems.

The study by Ma, Liu and Shang asks an interesting question why a person's thermal discomfort arises. It emphasizes the optimization of thermal comfort in the interior so that people consume less energy for heating or cooling rooms. Thanks to ANN in the study, they were able to predict a person's thermal well-being more accurately.

Petrova asks what all the data collected from Gigantum and Home2020 buildings mean for the design of future (and better) buildings. Her idea has a great potential, but at the same time it is a "monstrous" project, the biggest problems of which may be political unsustainability and ethical issues (project selection, system security, user rights).

\section{DISCUSSION}

The key idea of the cooperation between $\mathrm{Al}$ and the architect raises questions about the capabilities of $\mathrm{Al}$ - can it offer the architect something meaningful? Undoubtedly, there is a need for experts who prepare training datasets for Al [3] [13], select the optimal Al algorithms (ANN, ML etc.) and define their stratification. ANN with a small number of neurons and layers cannot solve new problems and, surprisingly, too many neurons can be an obstacle to finding a characteristic phenomenon or pattern. How to overcome these problems? The problem depicted in Figure 6 [37] is compared to a tourist who tries to descend from a high mountain but sees only one meter around him. The strategy is therefore to look around and find the steepest way (if you want to get down as quickly as possible). He repeats this process over and over until he finds his way down. The problem is if the tourist gets to the "pit" of the local optimum and not to the destination - the globally lowest place. The solution is to use several ANN networks that work together in one system. However, there are no objectively correct solutions, we are just looking for the best possible balance.

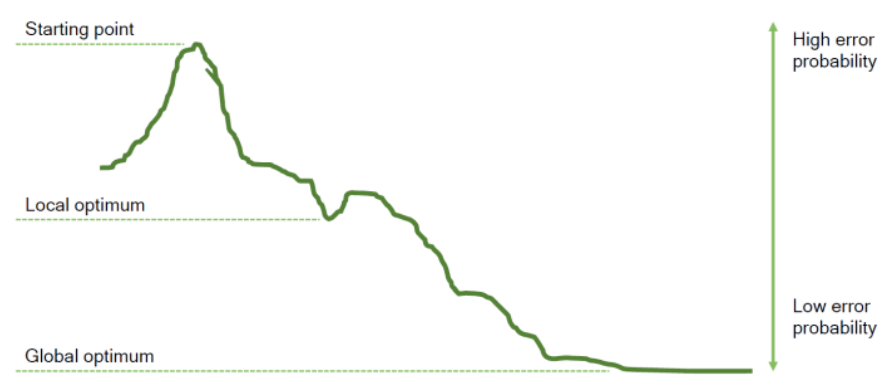

Figure 6: Overcoming problems with ANN, "Gradient descent". According to P. Boucher, EPRS. [37]

Questions about $\mathrm{Al}$ and its singularity from a global perspective can be "depressing" if we imagine a world that can be prospectively driven by superintelligence. However, the applicability of $\mathrm{Al}$ in solving certain types of problems is still at the beginning of development. The question of whether $\mathrm{Al}$ can understand the true meaning of concepts and perfectly simulate the human way of solving problems has not yet been answered. Multiple Als can cooperate and train with each other, multiple independent ANNs can cooperate, and even Al mutations can be generated that change the number of neurons and layers in the ANN structure (neuroevolution) [38]. However, we are still talking about problem-solving based on algorithms and statistics of the occurrence of a certain phenomenon from training sets, so this process will certainly not do without the supervision of a person who understands the problem. Another point of view suggests using Al differently, in re-interpretation of architectural works by applying machine learning tool(s) [39], so architects do not have to worry about unemployment (yet).

\section{CONCLUSION}

Al can work with various types of data (numbers, texts, graphic data, 3D objects), statistically evaluate them and find patterns of phenomena in that data. For follow-up research, the specific output of which should be the methodology of reducing the carbon footprint of the FAD building, the essential finding is that 
$\mathrm{Al}$ is able to identify connections that a human would be looking for for much longer or would not find at all. The prerequisite is the preparation of high-quality "datasets" for machine learning, ideally by a larger number of experts (to reduce bias). In the analysed studies, there is a consensus that Al can constantly improve its results and with increasing number of repetitions, the "noise" is reduced to an acceptable value.

Based on such knowledge, we dare to formulate the assumption that $\mathrm{Al}$, in cooperation with the BIM model, could, for example, predict the critical behaviour of a building user, based on the collected data on human thermal comfort. If we knew his point of discomfort, we could model different situations and see if they have a major impact on human behaviour (for example, if the change of interior colours in winter from cold to warm improves people's thermal comfort so much that energy consumption for heating is reduced, or whether sunny weather in summer provokes people to open windows, reducing the efficiency of air conditioning).

Prospectively, Al does not have to work just as a cool algorithm. In the study of Ma, Liu, and Shang we see an inspiring concept of humanism as a factor in reducing $\mathrm{CO} 2$ emissions, which they are trying to achieve with the help of AI. In the BIMBOT study, there is a futuristic vision of an architect who works only as a "supervisor" of Al. Even with the current Al skills, its results are limited only by our own experience.

\section{REFERENCES:}

[1] Sharma, R. (2020) "What is Artificial Intelligence? How does Artificial Intelligence work and how is Al used?", In: Medium. Available at: <https://bit.ly/2IBB3Ls> [Accessed: 2020-1115]

[2] Lu, Y., Wu, Z., Chang, R., Li, Y. (2017) "Building Information Modeling (BIM) for green buildings: A critical review and future direction. Automation in Construction", In: ResearchGate,

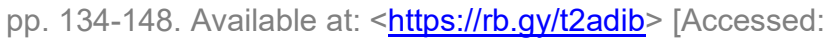
2020-11-15]

[3] Chaillou, S. (2020) "A tour of Al in Architecture - A Virtual Tour at the Arsenal Pavilion". Available at:

<https://bit.ly/2IDQC5x> [Accessed: 2020-11-15]

[4] Chaillou, S. (2020) In: Stanislaschaillou. Available at: <http://stanislaschaillou.com/> [Accessed: 2020-11-15]

[5] Chaillou, S. (2020) "Space Layouts \& GANS - GAN - enabled Floor Plan Generation. Towards Data Science", In: Aca-

demia. Available at: <https://bit.ly/36GSQsK> [Accessed 202011-15]

[6] Chaillou, S. (2019) Architecture \& Style: "A New Frontier for Al in Architecture, Harvard University", In: Academia. Available at: https://bit.ly/3kyBQtM [Accessed 2020-11-15]

[7] Frías, C., Peña, J., Sánchez, E., Almeida, L. (2020) "BIMBOT (Artificial intelligence applied to BIM design). EGE-

Expresión Gráfica en la Edificacon", In: ResearchGate.

Available at: < https://bit.ly/3f3oaG3> [Accessed 2020-11-15]

[8] Mia, G., Liu, Y., Shang, S. (2019) "A Building Information Model (BIM) and Artificial Neural Network (ANN) Based System for Personal Thermal Comfort Evaluation and Energy Efficient Design of Interior Space", In: ResearchGate, 11, 4972. Available at: < https://bit.ly/2IFCdVY> [Accessed 2020-11-15]

[9] Petrova, E. (2019) "Al for BIM-based sustainable building design: Integrating knowledge discovery and semantic data modelling for evidence-based decision support (Thesis for PhD in Civil Engineering)", Aalborg University, Denmark, In: ResearchGate. Available at: < https://bit.ly/38Is4mr> [Accessed 2020-11-15]

[10] Technopedia, In: Technopedia.com. Available at: https://bit.ly/35vcw3E [Accessed 2020-11-15]

[11] Chaillou, S. (2019) "The Advent of Architectural Al: A Historical Perspective. Harvard University", In: Academia 2. Available at: <https://bit.ly/2IE6Fjo > [Accessed 2020-11-15]. [12] Sonix, In: sonix.ai - https://bit.ly/3psFcCe [Accessed 202011-15]

[13] Boucher, P. (2019) "How artificial intelligence works", EPRS - European Parliamentary Research Service, In: europarl.europa 2. Available at: < https://rb.gy/wg2jff> [Accessed 2020-11-15]

[14] Ibid., In: europarl.europa 8. Available at: $<$ https://rb.gy/wg2jff> [Accessed 2020-11-15]

[15] Thinkautomation, In: thinkautomation.com https://bit.ly/3f5AmpF. [Accessed 2020-11-15]

[16] Boucher, P. (2019) "How artificial intelligence works", EPRS - European Parliamentary Research Service, In: europarl.europa 4-5. Available at: < https://rb.gy/wg2jff> [Accessed 2020-11-15]

[17] Chaillou, S. (2020b) "Space Layouts \& GANS - GAN enabled Floor Plan Generation. Towards Data Science", In: Academia 2. Available at: <https://bit.ly/36GSQsK> [Accessed 2020-11-15]

[18] Frías, C., Peña, J., Sánchez, E., Almeida, L. (2020) "BIMBOT (Artificial intelligence applied to BIM design). EGE-

Expresión Gráfica en la Edificacon", In: ResearchGate 1.

Available at: < https://bit.ly/3f3oaG3> [Accessed 2020-11-15]

[19] Ibid., In: ResearchGate 4-6. Available at: $<$ https://bit.ly/3f3oaG3> [Accessed 2020-11-15]

[20] Petrova E. (2019) "Al for BIM-based sustainable building design: Integrating knowledge discovery and semantic data modelling for evidence-based decision support (Thesis for PhD in Civil Engineering)", Aalborg University, Denmark, In:

ResearchGate 7-8. Available at: <https://bit.ly/38ls4mr>

[Accessed 2020-11-15]

[21] Ibid., In: ResearchGate 109-111. Available at:

$<$ https://bit.ly/38ls4mr>

[Accessed 2020-11-15]

[22] Ibid., In: ResearchGate 21-22. Available at:

<https://bit.ly/38ls4mr>

[Accessed 2020-11-15]

[23] Ibid., In: ResearchGate 22-25. Available at:

<https://bit.ly/38Is4mr>

[Accessed 2020-11-15]

[24] Ibid., In: Research Gate 29-30. Available at:

<https://bit.ly/38/s4mr>

[Accessed 2020-11-15]

[25] Ibid., In: ResearchGate 32. Available at: <https://bit.ly/38ls4mr > [Accessed 2020-11-15]

[26] Jin, C., Xu, M., Lin, L. \& Zhou, X. (2018) "Exploring BIM data by graph-based unsupervised learning", In: Proceedings of the 7th International Conference on Pattern Recognition Applications and Methods In: Scitepress (ICPRAM 2018), pp. 582-589. Available at: <https://bit.ly/3eZXRk5 > [Accessed 2020-11-15]

[27] Liu, Y., Huang, Y., Stouffs, R. (2015) "Using a data-driven approach to support the design of energy-efficient buildings", In: itcon Journal of Information Technology in Construction (ITcon), Special issue ECPPM 2014-10th European Conference on Product and Process Modelling 20, pp. 80-96. Available at: https://rb.gy/un3lcs [Accessed 2020-11-15]

[28] Technopedia, In: Technopedia.com -

https://bit.ly/2H4ocRx [Accessed 2020-11-15] 
[29] Petrova, E. (2019) "Al for BIM-based sustainable building design: Integrating knowledge discovery and semantic data modelling for evidence-based decision support (Thesis for PhD in Civil Engineering), Aalborg University, Denmark, In:

ResearchGate 38-39. Available at: <https://bit.ly/38ls4mr $>$ [Accessed 2020-11-15]

[30] Technopedia, In: Technopedia.com -

https://bit.ly/2KcwmZh [Accessed 2020-11-15]

[31] Petrova, E. (2019) "Al for BIM-based sustainable building design: Integrating knowledge discovery and semantic data modelling for evidence-based decision support (Thesis for PhD in Civil Engineering)". Aalborg University, Denmark, In:

ResearchGate 60-66. Available at: <https://bit.ly/38ls4mr > [Accessed 2020-11-15]

[32] Ibid., In: ResearchGate 66-68. Available at: <https://bit.ly/38ls4mr>

[Accessed 2020-11-15]

[33] Ibid., In: ResearchGate 69-70. Available at: <https://bit.ly/38ls4mr>

[Accessed 2020-11-15]

[34] Ibid., In: ResearchGate 73. Available at:

<https://bit.ly/38ls4mr > [Accessed 2020-11-15]

[35] Ibid., In: ResearchGate 78-82. Available at: <https://bit.ly/38ls4mr>

[Accessed 2020-11-15]

[36] Ibid., In: ResearchGate 83-98. Available at:

$<$ https://bit.ly/38ls4mr>

[Accessed 2020-11-15]

[37] Boucher, P. (2019) "How artificial intelligence works",

EPRS - European Parliamentary Research Service, In: europarl.europa 3. Available at: < https://rb.gy/wg2iff> [Accessed 2020-11-15]

[38] Ibid., In: europarl.europa 6. Available at: $<$ https://rb.gy/wg2jff > [Accessed 2020-11-15] [39] Hajtmanek, R. (2020) "Re-interpretation of architectural works by machine learning tool”, In: PEŘINKOVÁ, M. --

JÜTTNEROVÁ SANDRA, -- VIDECKÁ LUCIE. "Architecture in Perspective 2020. Proceedings of the International Conference", Ostrava: Vysoká škola báňská - Technická univerzita Ostrava, pp. 328-332, ISBN 978-80-248-4450-3.

[40] Center for contextual innovation, In: proftgs.blogspot.com Available at: <https://bit.ly/3b5w5Ca $>$ [Accessed 2020-11-15]

[41] Watch blog, In: blog.gao.gov. Available at:

$<$ https://bit.ly/37YXWSW > [Accessed 2020-11-15] 